\title{
In silico drug repurposing of anticancer drug 5-FU and analogues against SARS- CoV-2 main protease
}

\begin{abstract}
Aristote Matondo ${ }^{\mathrm{a}}$, Washington Dendera ${ }^{\mathrm{b}}$, Bienfait Kabuyaya Isamura ${ }^{\mathrm{b}}$, Koto-te-Nyiwa Ngbolua $^{c}$, Hilaire V.S. Mambo ${ }^{\text {a }}$, Mayaliwa Muzomwe ${ }^{\text {a }}$, Virima Mudogo ${ }^{\text {a }}$
\end{abstract}

\footnotetext{
${ }^{\text {a }}$ Department of Chemistry, University of Kinshasa, Kinshasa XI, Democratic Republic of the Congo

${ }^{\mathrm{b}}$ Department of Chemistry, Rhodes University, 6140, Makhanda, South Africa

${ }^{\mathrm{c}}$ Department of Biology, University of Kinshasa, Kinshasa XI, Democratic Republic of the Congo
}

*Correspondence to: aristote.matondo@unikin.ac.cd

\begin{abstract}
The pressing need to find effective drugs against the current deadly COVID-19 disease has recently motivated numerous studies using different approaches to address the problem. One time-saving and less costly strategy is the drug repurposing, which consists in finding new therapeutic uses for approved drugs. Following the same trend, this study has investigated the potential inhibitory activity of 5-FU and its analogues against the SARS-CoV-2 main protease as well as their profile of druggability using molecular docking and ADMET methods. From the calculations performed, four candidates showed promising results with respect to the binding affinity to the target protease, 3CLpro, the therapeutic profile of druggability and safety. Further in-vitro and in-vivo investigations are needed that may clarify their possible mechanism of the pharmacological action to combat COVID-19.
\end{abstract}

Keywords: Drug repurposing, 5-fluorouracil, SARS-CoV-2, COVID-19, molecular docking, ADMET 


\section{Introduction}

Over the last two decades, two prior outbreaks have emerged in the world as epidemics; Severe Acute Respiratory Syndrome Coronavirus-1 (SARS-CoV-1) which was first reported in November 2002 in Guangdong, China, and Middle Eastern Respiratory Syndrome (MERS$\mathrm{CoV}$ ) which was first reported in Saudi Arabia in 2012 [1]. The current outbreak of the novel coronavirus disease (COVID-19) was first reported in December 2019 in Wuhan, China, and is caused by a novel Severe Acute Respiratory Syndrome, named SARS-CoV-2 [2]. On the $02^{\text {nd }}$ of December 2021, www.woldometers.info/coronavirus reported that 5,245,545 people had died from the disease. To date, no drug has yet been found and the COVID-19 remains a global pandemic with little treatment options. However, the first generation of COVID-19 vaccines has emerged and several countries already use them. Unfortunately, several cases of vaccine withdrawal have been reported, due to problems such as thrombosis in vaccinated individuals [3]. Such problems, even minor, have increased the population reluctance against the COVID19 vaccine, already observed in several parts of the world, especially in Africa [4]. Such reluctance against the COVID-19 vaccine reminds us of the urgent need to develop antiCOVID-19 agents for the prevention of the outbreak and stop viral infections. On top of that, two frightening variants of the initial SARS-CoV-2 have been recently observed, namely the Delta and Omicron mutated viruses.

In order to tackle the virus and its new variants, scientists are coming up with different strategies. One of the widely used is to assess the efficiency of plant secondary metabolites and other nutraceuticals against SARS-CoV-2 proteins [5,6]. Another strategy, known as drug repurposing, consists in ascribing new therapeutic uses for approved/available drugs [7]. This strategy, known as drug repurposing constitutes an effective drug discovery strategy as it significantly shortens the time, increases the success rate, reduces the cost compared to de novo drug discovery and randomized clinical trials $[\mathbf{7 , 8}]$. It is worth noting that the drug repurposing technique follows two paradigms: on-target and off-target. In on-target concept, a single drug molecule is applied to a new therapeutic indication with the same biological target. On the other hand, a single drug molecule or a drug candidate interacts with one or multiple new targets, out of the original scope, for new therapeutic indications. In recent years, the drug repurposing strategy has allowed many pharmaceutical companies to develop new drugs based on the discovery of novel biological targets [9].

Since the COVID-19 outbreak, the drug repurposing approach is increasingly used in an attempt to find an effective treatment against the disease. For example, several drugs with antimalarial [10] or antiviral [11] properties have been found to have an anti-COVID effect. 
Recently, various drug repurposing studies that looked at anti-cancer drugs and their possible effect against COVID-19 revealed that many of them could be used in the fight against COVID19 [12-14]. Furthermore, according to a hypothesis formulated by Ahmad, the combination of the anticancer drug 5-fluorouracil (5-FU) with deoxyribonucleosides and deoxyribose could represent therapeutic options for the coronavirus disease [15]. Acting as anticancer drug, 5-FU is converted to 5-fluoro-2'-deoxyuridine-5'-monophosphate (FdUMP) which then forms a complex with the target enzyme thymidylate synthase (TS) [16]. Therefore, the interest has been turned towards the anticancer drug 5-fluorouracil (5-FU) and some of its analogues previously reported [17].

We report in this communication the interaction of anticancer properties compounds 5-FU and nineteen of its analogues with the COVID-19 main protease (Mpro) or the 3-ChymotrypsinLike protease (3CLpro) using molecular docking method. Pharmacokinetics of the potential candidates based on their docking score is then carried out to establish their ADMET (absorption, distribution, metabolism, excretion and toxicity) profile.

\section{Materials and methods}

\subsection{Preparation of ligands}

The 2D structures of 5-FU and its analogues are displayed in Figure 1, and were drawn using ChemDraw Pro 16.0 software, then converted to 3D structures and saved as .sdf format. Further, the 3D structures of selected compounds were subjected to full geometry optimizations by semi empirical methods using PM6 (Parametrization Method 6) [18]. It is worth noting that energy minimization process of ligands at this step is essential as it contributes to the removal of unfavorable contacts, which may affect the binding ability of the ligand. All the optimized structures were visualizes using Chemcraft software [19] and are shown in Figure 2.

\subsection{Preparation of the target protein, 3CLpro}

The three-dimensional crystal structure of the protein, 3-Chymotrypsin-Like protease (3CLpro) or the COVID-19 virus main protease (Mpro) was retrieved from Protein Data Bank (PDB ID: 6LU7) and imported into Chimera for visualizing the binding domain of the complex and identifying the amino acids in the binding pocket. Note that 3CLpro is among the most studied SARS-CoV-2 proteases [5,6]. Discovery Studio [20] functionalities were employed to clean and prepare the protein. This step involved the energy minimization treatment of the protein and the removal of both the native ligand of the protease and solvating water molecules. The optimized protein was saved in .pdbqt format and imported to PyRx Autodock Vina for molecular docking. 
<smiles>O=c1[nH]cc(F)c(=O)[nH]1</smiles><smiles></smiles>

5-FU, 20<smiles>O=c1[nH]c(=O)n(C2CCCO2)cc1F</smiles>

2<smiles>C=C(C)OC(=O)OCn1cc(F)c(=O)[nH]c1=O</smiles>

3<smiles>Nc1nc(=O)n(C2CCC(CO)O2)cc1F</smiles>

4<smiles>O=c1nc(O)c(F)cn1C1OC2C(CO)OC1C2O</smiles>

6<smiles>C=C(C)OC(=O)OCn1cc(F)c(=O)n(CC)c1=O</smiles><smiles>Nc1nc(=O)n(C2CC(O)C(CO)O2)cc1F</smiles>

7<smiles>COC(=O)Cn1cc(F)c(=O)[nH]c1=O</smiles>

8
5<smiles>CO[C@H](O)Cn1cc(F)c(=O)[nH]c1=O</smiles><smiles>O=c1[nH]c(=O)n(CCO)cc1F</smiles>

10<smiles>NC(=O)Cn1cc(F)c(=O)[nH]c1=O</smiles>

11<smiles>O=C1NC(=O)C(F)(n2cc(F)c(=O)[nH]c2=O)C(O)N1</smiles><smiles>Cc1ccccc1C(=O)n1c(=O)[nH]cc(F)c1=O</smiles>

13<smiles>O=c1[nH]cc(F)c(=O)n1CCCNc1ccc([N+](=O)[O-])cc1[N+](=O)[O-]</smiles>

14

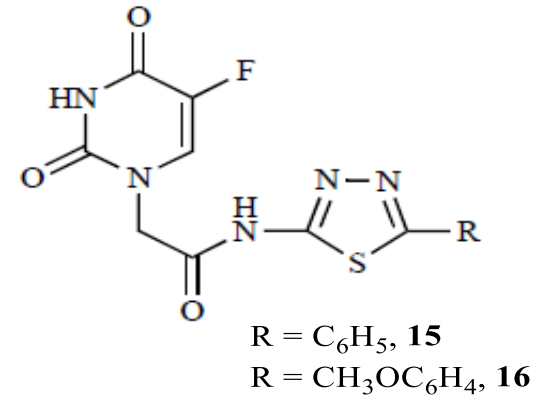<smiles>O=C(CCO)OCn1c(=O)c(F)cn(C2CCCO2)c1=O</smiles>

17<smiles>COC(=O)CNC(=O)Cn1cc(F)c(=O)[nH]c1=O</smiles>

19

Figure 1. 2D structures of 5-FU and its selected analogues 


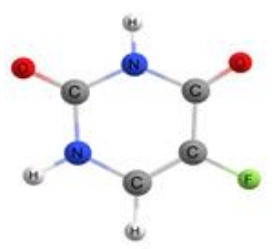

5-FU, 20

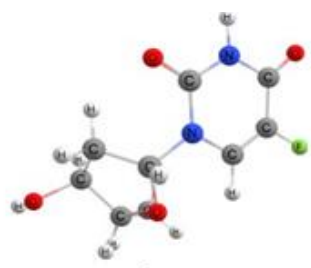

1
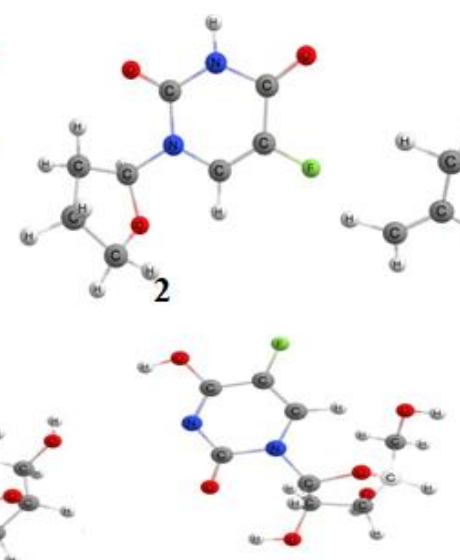

6

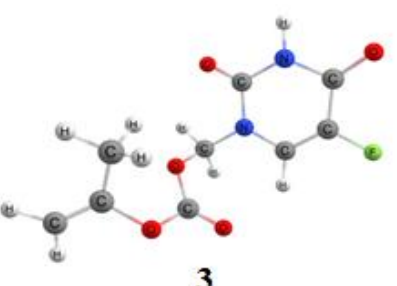

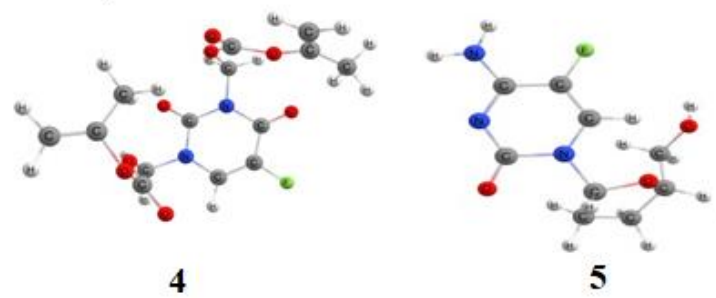
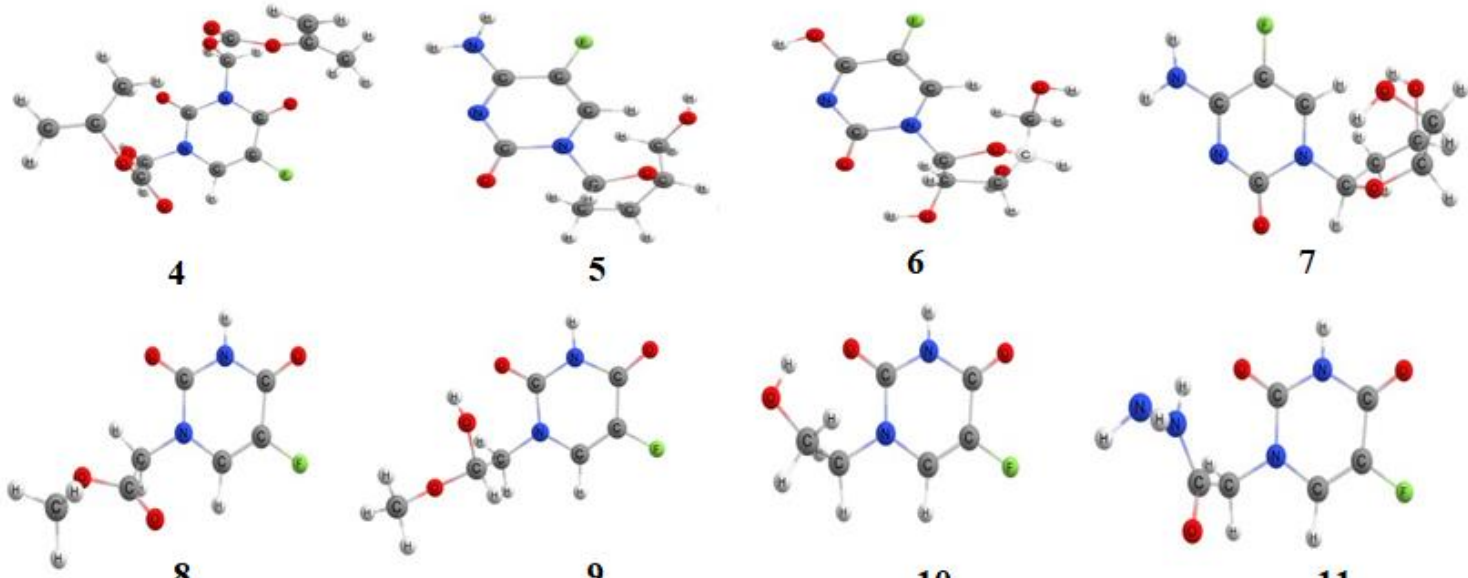

7

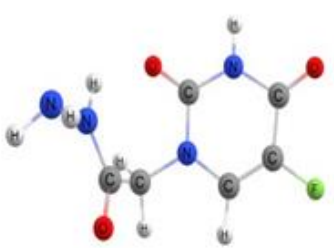

10

11

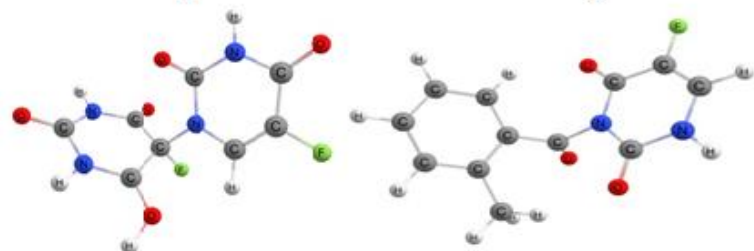

12

13

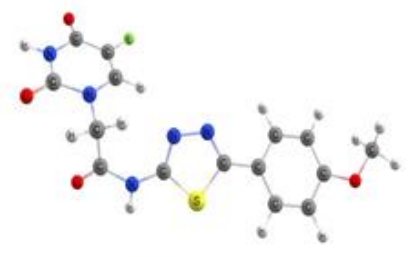

16

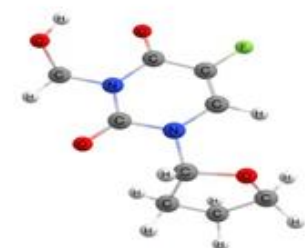

17

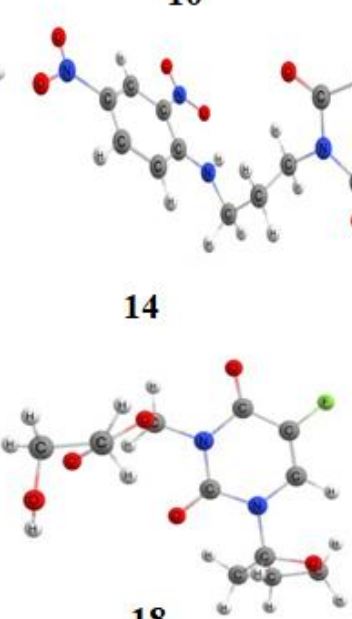

18

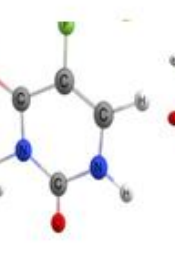

11

\section{1}




\section{Results and discussion}

\subsection{Energetics and geometries}

The binding energy (BEs) of complexes formed between 5-FU and nineteen of its analogues with the SARS-CoV-2' protease 3CLpro are shown in Figure 3. The latter also depicts the $3 \mathrm{D}$ representation of interactions of the most binding complexes. The binding energies range from -4.8 to $-7.9 \mathrm{kcal} / \mathrm{mol}$. These negative values suggest an overall favorable and spontaneous packing of the ligands in the inhibitory site. 5-FU, taken as a prototype ligand, is the compound that forms the least stable complex with the enzyme 3CLpro. Another ligand that is automatically a bad candidate to treat COVID-19 is ligand 12, because it occupies, together with 5 -FU the last position with binding affinity equal to $-4.8 \mathrm{kcal} / \mathrm{mol}$.

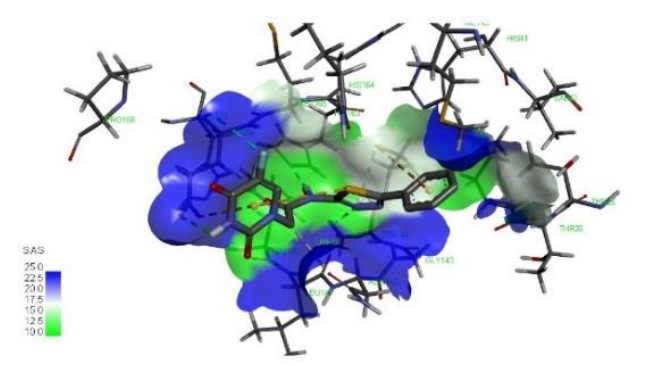

15
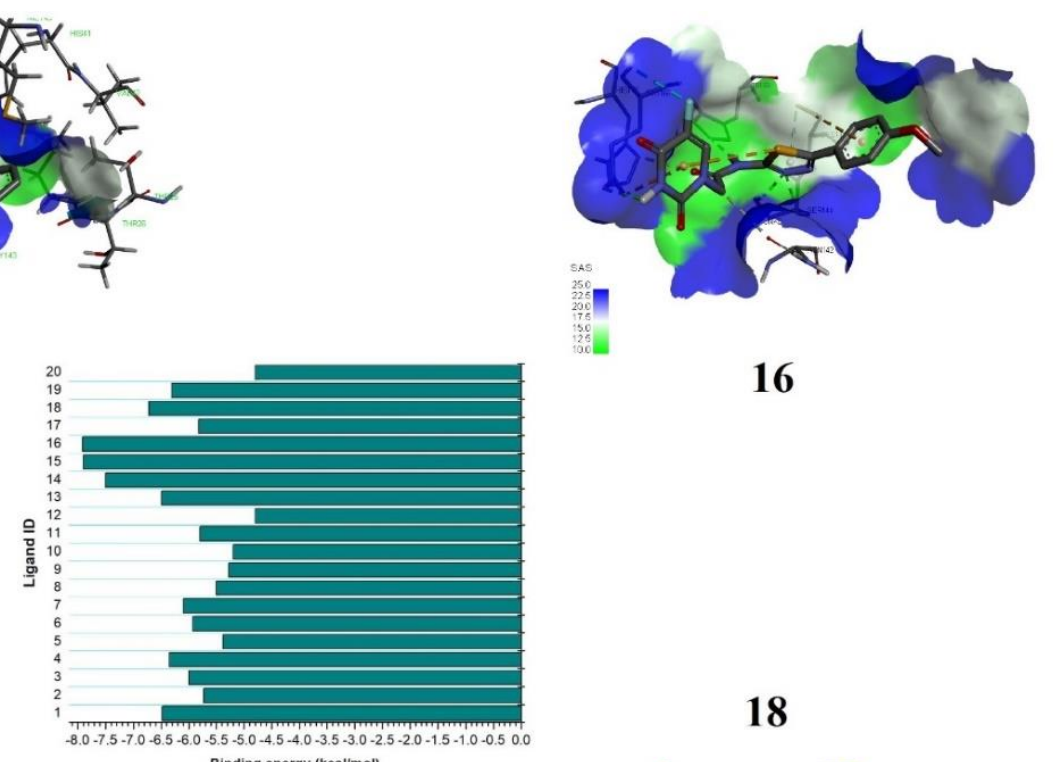

16

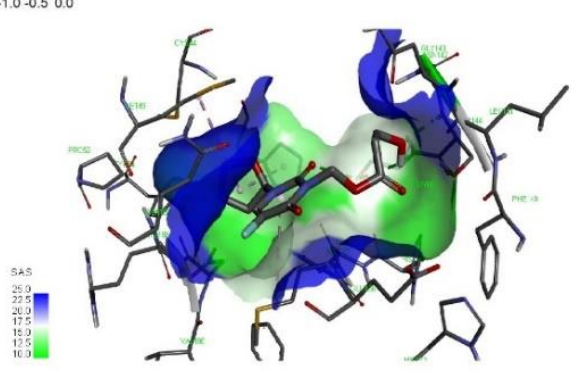

Figure 3. Binding energy of all ligands with the 3CLpro and the 3D representation of interactions of the most binding complexes

Ligands that may be of special interest are ligands $\mathbf{1 5}$ and $\mathbf{1 6}$ since their binding affinity holds the first position $(-7.9 \mathrm{kcal} / \mathrm{mol})$, followed by ligand 14 that holds the second position $(-7.5$ $\mathrm{kcal} / \mathrm{mol}$ ) and ligand 18 with the binding affinity assessed at $-6.7 \mathrm{kcal} / \mathrm{mol}$. It is clear from 
Figure 3 that these four ligands also lay perfectly well in the pocket, which a desired feature for effective activity.

By inspection of the binding mode of top 4 ranked compounds shown in Figure 4, hydrogen bonding, van der Walls and hydrophobic interactions were the main driving forces in the stability of complexes. The two most stables complexes show remarkable similarity in terms of both binding energy and binding mode. Ligands $\mathbf{1 5}$ and $\mathbf{1 6}$ formed nine hydrogen bonds with the amino acids residues GLU166, HIS163, SER144, GLY143, HIS172, ASN142, CYS145 and LEU141. In fact, the crystal structure of 3CLpro retrieved from PDB revealed important residues for binding, which are THR24, THR25, PHE140, ASN142, GLY143, CYS145, HIS163, HIS164, GLU166 and HIS172 [5,22].

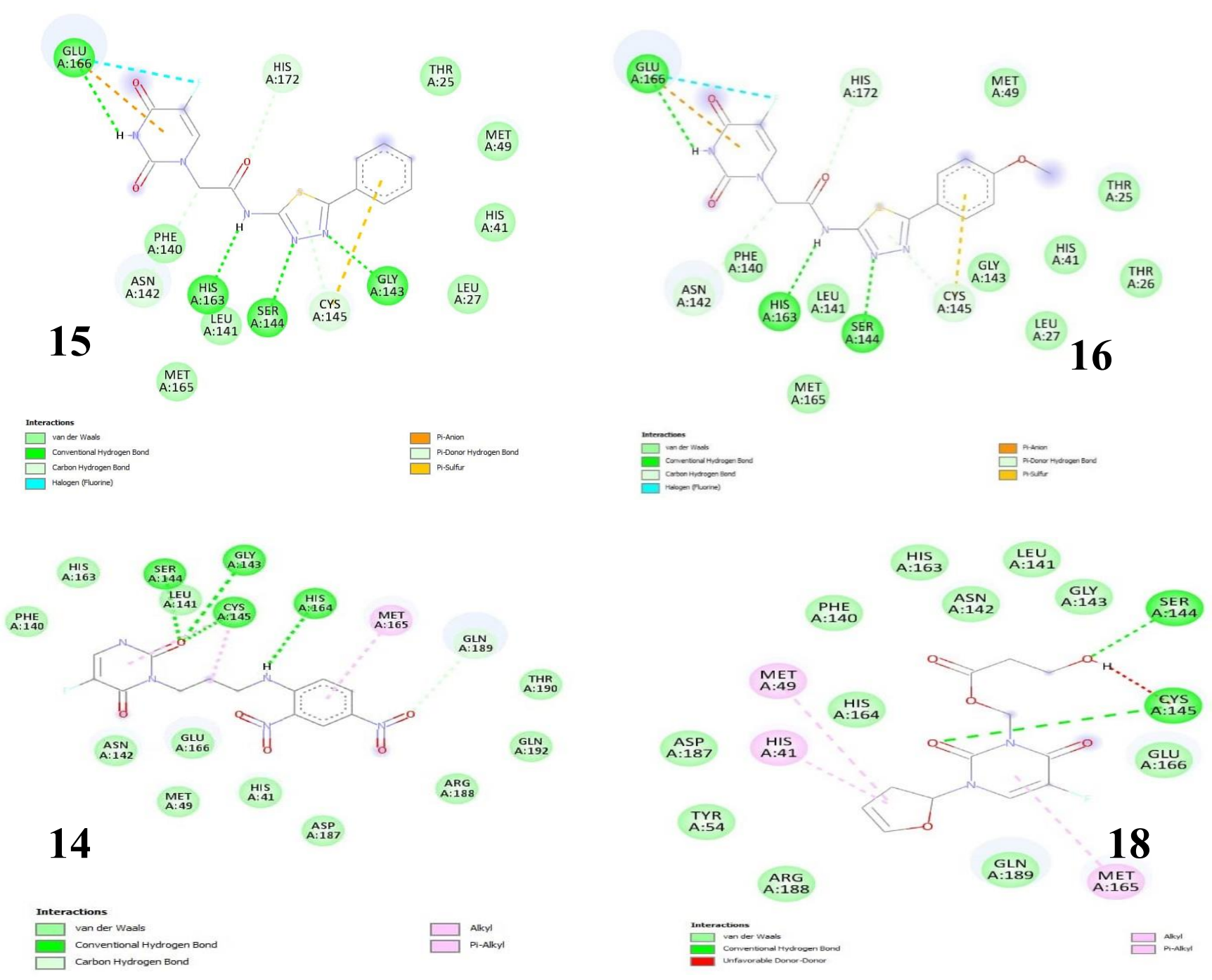

Figure 4. 2D representation of the interaction of top 4 ranked compounds with 3CLpro

One can see that six of these amino acids residues are involved in hydrogen bonding interaction in ligands 15 and 16, while three of them, PHE140, THR25 and LEU141 are involved in van der Walls interactions. With respect to ligands 14 and $\mathbf{1 8}$, the former formed five hydrogen 
bonds with SER144, GLY143, CYS145, HIS164 and GLN189 while the latter merely formed two hydrogen bonds with SER144 and CYS145.

Therefore, there is no doubt that the hydrogen bonding interaction makes a substantial contribution to the total stability of complexes since increased number of hydrogen bonds corresponds to better and strong binding, especially for binding sites composed of polar residues. Another interaction that strengthens the binding affinity of ligands-receptor stems from van der Walls interactions. Nevertheless, hydrophobic interactions, although present, only slightly contribute to the overall stabilization of the protein-ligand complexes.

\subsection{Physicochemical properties and ADME-T profile}

In drug design, the main challenge is to develop one or more compounds with the desired drug properties. In addition to high affinity for the target protein, the compound must have an appropriate selectivity profile, be able to reach the site of action and have acceptable drug properties. That's one of the major objectives of the clinical phase in drug discovery, aiming to guarantee the compound under trial meets the required criteria and a good therapeutic profile of druggability. The pharmacokinetic profile of a compound defines its properties of absorption, distribution, metabolism and excretion (ADME). In addition to the ADME, the ligand to be selected as a hit must be non-carcinogenic and non-hepatotoxic, that is, non-toxic. In the present investigation, the pharmacokinetic parameters and the toxicity assessment of the four best docked ligands were obtained using online SwissADME [23] and the pkCSM server [24], respectively. All these parameters are gathered in Table 1, values on bold are those obtained with pkCSM server.

Based on physicochemical parameters, druglikeness properties were evaluated according to Lipinski's rule-of-five: molecular weight < 500 Daltons (Da), calculated lipophilicity (Log P) $<5$, number of hydrogen-bond acceptors (HBA) $<10$ and number of hydrogen bond donors $(\mathrm{HBD})<5$ [25]. The result reveals that the four high dock-scoring ligands exhibit good bioavailability and appropriate druglikeness properties since they fully obey the Lipinski's ruleof-five. 
Table 1. Physicochemical parameter and ADME-T profiles of the four ranked ligands

\begin{tabular}{|c|c|c|c|c|}
\hline Physicochem. Parameter & Ligand 15 & Ligand 16 & Ligand 14 & Ligand 18 \\
\hline Formula & $\mathrm{C}_{14} \mathrm{H}_{10} \mathrm{FN}_{5} \mathrm{O}_{3} \mathrm{~S}$ & $\mathrm{C}_{15} \mathrm{H}_{12} \mathrm{FN}_{5} \mathrm{O}_{4} \mathrm{~S}$ & $\mathrm{C}_{13} \mathrm{H}_{12} \mathrm{FN}_{5} \mathrm{O}_{6}$ & $\mathrm{C}_{13} \mathrm{H}_{16} \mathrm{FNO}_{6}$ \\
\hline MW (Da) & 347.32 & 377.35 & 353.26 & 301.27 \\
\hline $\log P$ & $1.21 / \mathbf{0 . 8 3}$ & $1.56 / \mathbf{0 . 8 4}$ & $1.40 / \mathbf{0 . 9 9}$ & $1.96 / \mathbf{0 . 1 1}$ \\
\hline HBD & $2 / 2$ & $2 / 2$ & $2 / 2$ & $1 / 1$ \\
\hline HBA & $6 / 7$ & $7 / 8$ & $7 / 8$ & $7 / 6$ \\
\hline $\operatorname{PSA}(\AA)$ & 137.17 & 148.65 & 137.58 & 119.85 \\
\hline \multicolumn{5}{|l|}{ Pharmacokinetics } \\
\hline GI absorption & High & Low & Low & High \\
\hline Water solubility $(\log S)$ & -2.61 & -2.70 & -4.00 & -2.11 \\
\hline HIA (\%) & 75.46 & 64.13 & 64.30 & 76.34 \\
\hline BBB permeant & $\mathrm{No} /-1.446$ & $\mathrm{No} /-\mathbf{1 . 3 3 5}$ & $\mathrm{No} /-\mathbf{1 . 3 4 5}$ & $\mathrm{No} /-\mathbf{0 . 9 4 3}$ \\
\hline Skin perm. $(\log \mathrm{kp}, \mathrm{cm} / \mathrm{h})$ & -2.74 & -2.74 & -2.78 & -2.93 \\
\hline Bioavailability score & 0.55 & 0.55 & 0.55 & 0.55 \\
\hline CYP2D6 & No & No & No & No \\
\hline CYP3A4 & No & No & No & No \\
\hline \multicolumn{5}{|l|}{ Toxicity } \\
\hline Ames test & No & No & No & No \\
\hline Hepatotoxicity & Yes & Yes & No & No \\
\hline Carcinogenicity & No & No & Yes & No \\
\hline $\mathrm{LD}_{50}$, in $\mathrm{mol} / \mathrm{kg}$ and $\mathrm{mg} / \mathrm{kg}$ & $\begin{array}{l}2.033 \\
1017\end{array}$ & $\begin{array}{l}1.900 \\
950\end{array}$ & $\begin{array}{l}2.833 \\
1417\end{array}$ & $\begin{array}{l}2.770 \\
1385\end{array}$ \\
\hline
\end{tabular}

The polar surface area (PSA) is an extremely instructive parameter for optimal drug absorption whose value cannot go beyond $140 \AA$ [26]. The predicted values of PSA although quite high are lower than $140 \AA$, except for ligand 16 (148.65 $\AA$ ). Moreover, the GI absorption of a drug is important when the drug is intended to be administered via oral route. Our study reveals that only two analogues of 5-FU among the best docked compounds are expected to be rapidly absorbed from GI tract (ligands $\mathbf{1 5}$ and 18). However, from the water solubility data of the ligands obtained from pkCSM server, only ligand $\mathbf{1 4}$ is poorly soluble as the $\log \mathrm{S}$ value is not less than -4. Similarly, the human intestine absorption (HIA) values reveal that hits $\mathbf{1 5}$ and $\mathbf{1 8}$ have higher probability of being absorbed by human intestine (76\%) than hits 16 and 14 (64 $\%)$. The Blood-Brain Barrier (BBB) permeability determines whether a molecule will exert its action, either beneficial or detrimental, on brain. Crossing of conventional anticancer molecules 
through the BBB can cause significant destruction of the neurons in brain producing serious neuro-consequence [27]. Values of BBB permeability for the four retained molecules are all negative so that compounds are expected to produce no neurotoxicity in brain, since they will not cross the BBB. The recommended value for the skin permeability of a drug-molecule, which is an important consideration for improving drug efficacy, is set at more than $-2.5 \mathrm{~cm} / \mathrm{h}$ [24]. It can be seen from Table 1 that the four compounds will produce little or no skin toxicity since they will not penetrate the skin layer very easily. The bioavailability score which is evaluated to 0.55 confirms that the four ligands have good absorption and distribution since all potential candidates may have more than $10 \%$ of bioavailability in rat $[\mathbf{2 8 , 2 9 ]}$.

Turning now to the metabolism and toxicity, it was reported that Cytochrome enzymes CYP2D6 and CYP3A4 are the major responsible for drug metabolism [26]. Interestingly, the four best candidates are found to be non-inhibitors of CYP2D6 and CYP3A4. The outcome on the toxicity is quite encouraging. In fact, none of the four compounds is likely to induce mutagenicity, and all of them are non-carcinogenic except ligand 14. With regards to the hepatotoxicity, the two best docked ligands among the top four ranked ligands are found to be capable to confer hepatotoxicity. Lastly, the values of the oral rat acute toxicity expressed in term of $50 \%$ of lethal dose $\left(\mathrm{LD}_{50}\right)$ are all classified in category or class 4 , meaning that after administration, compounds are expected to be slightly toxic (Globally Harmonized System: 300 $<$ Category $4 \leq 2000$ ) and can thus be considered as safe.

\section{Conclusion}

This study was carried out to investigate the interaction of the FDA approved anticancer drug 5-fluorouracil and some of its analogues with the first resolved COVID-19 crystal structure (3CLpro or main protease) using molecular docking method, with the hope that they can act as anticancer compounds by inhibiting the COVID-19 protease. The result of this drug repurposing study showed that 5-FU and most of its analogues cannot act as antiviral drug to tackle the COVID-19. Our study revealed that from a set of twenty compounds included 5-FU, only four analogues, ligands 15, 16,14 and 18 are found to be potential candidates since each formed stable complex with the target protease, 3CLpro. More importantly, the pharmacokinetic behavior of the four best docked ligands revealed that they generally have good therapeutic profile of druggability and are safe. 


\section{References}

[1] D.S. Hui, E.I. Azhar, Y.J. Kim, Z.A. Memish, M.D. Oh, A. Zumla, Middle East respiratory syndrome coronavirus: risk factors and determinants of primary, household, and nosocomial transmission, Lancet Infect. Dis. 18 (2018) e217- 27.

[2] W. Di, W. Tiantian, L. Qun, Y. Zhicong, The SARS-CoV-2 outbreak: what we know, Int. J. Infect. Dis. 94 (2020) 44-48.

[3] Z.A. Abdulla, S.M. Al-Bashir, N.S. Al-Salih, A.A. Aldamen, M.Z. Abdulazeez, A Summary of the SARS-CoV-2 Vaccines and Technologies Available or under Development, Pathogens 10 (2021) 788-809.

[4] F. Ketterer, P. Trefois, M-Ch. Miermans, M. Vanmeerbeek, D. Giet, les réticences à la vaccination : approche du phénomène à travers les données de la littérature, Rev. Med. Liège 68 (2013) 74-78.

[5] P.T. Mpiana, K.N. Ngbolua, D.S.T. Tshibangu, J.T. Kilembe, B.Z. Gbolo, D.T. Mwanangombo, C.L. Inkoto, E.M. Lengbiye, C.L. Mbadiko, A. Matondo, G.N. Bongo, D.D. Tshilanda, Identification of potential inhibitors of SARS-CoV-2 main protease from Aloe vera compounds: A molecular docking study, Chem. Phys. Lett. 754 (2020) 137751.

[6] F.R. Bhuiyan, S. Howlader, T. Raihan, M. Hasan, Plants Metabolites: Possibility of Natural Therapeutics Against the COVID-19 Pandemic, Front. Med. 7 (2020) 444-469.

[7] T.U. Singh, S. Parida, M.C. Lingaraju, M. Kesavan, D. Kumar, R.K. Singh, Drug repurposing approach to fight COVID-19, Pharmacol. Rep. (2020) https://doi.org/10.1007/s43440-020-00155-6.

[8] M. Rudrapal, S.J. Khairnar, A.G. Jadhav, Drug Repurposing (DR): An Emerging Approach in Drug Discovery, IntechOpen (2020) https://doi.org/10.5772/intechopen.93193.

[9] T.T. Ashburn, K.B. Thor, Drug repositioning: Identifying and developing new uses for existing drugs. Nature Reviews, Drug Discov. 3 (2014) 673-683.

[10] P. Schlagenhauf, M.P. Grobusch, J.D. Maier, P. Gautret, Repurposing antimalarials and other drugs for COVID-19, Trav. Med. Infect. Dis. 34 (2020) 101658.

[11] S. Jeon, M. Ko, J. Lee, I. Choi, S.Y. Byun, S. Park, D. Shum, S. Kim, Identification of Antiviral Drug Candidates against SARS-CoV-2 from FDA-Approved Drugs. Antimicrob. Agents Chemother. 64 (2020) e00819-00820, https://doi.org/10.1128/AAC.00819-20.

[12] K. El Bairi, D. Trapani, A. Petrillo, C. Le Page, H. Zbakh, B. Daniele, R. Belbaraka, G. Curigliano, S. Afqir, Repurposing anticancer drugs for the management of COVID-19, Eur. J. Cancer 141 (2020) 40-61.

[13] G. Ciliberto, R. Mancini, M.G. Paggi, Drug repurposing against COVID-19: focus on anticancer agents, J Exp Clin Cancer Res. 39 (2020) 86-94.

[14] K.S. Saini, C. Lanza, M. Romano, et al, Repurposing anticancer drugs for COVID-19 induced inflammation, immune dysfunction, and coagulopathy, Br. J. Canc. 2020:1-4. https: //doi.org/10.1038/s41416-020-0948-X.

[15] S.I. Ahmad, 5-Fluorouracil in combination with deoxyribonucleosides and deoxyribose as possible therapeutic options for the Coronavirus, COVID-19 infection, Med. Hypotheses 142 (2020) 109754.

[16] R.B. Diasio, B.E. Harris, Clinical pharmacology of 5-fluorouracil, Clin. Pharmacokinet. 6 (1989) 215-237.

[17] X. Pan, C. Wang, F. Wang, P. Li, Z. Hu, Y. Shan, J. Zhang. Development of 5-Fluorouracil Derivatives as Anticancer Agents, Curr. Med. Chem. 18 (2011) 4538-4556.

[18] J. Rezac, J. Fanfrlı,, D. Salahub, P. Hobza, Semiempirical Quantum Chemical PM6 Method Augmented by Dispersion and H-Bonding Correction Terms Reliably Describes Various Types of Noncovalent Complexes, J. Chem. Theory Comput. 5 (2009) 1749-1760.

[19] G.A. Zhurko, D.A. Zhurko, Chemcraft Program, Academic version 1.8, 2014, available at: http://www.Chemcraftprogram.com. 
[20] D.S. Biovia, Discovery Studio Visualizer, San Diego, CA, USA, 2017.

[21] O. Trott, A.J. Olson, AutoDock Vina: improving the speed and accuracy of docking with a new scoring function, efficient optimization, and multithreading. J. Comput. Chem. 31 (2010) 455-461.

[22] A. Matondo, J.T. Kilembe, D.T. Mwanangombo, B.M. Nsimba, D.T. Mawete, B.Z. Gbolo, G.N. Bongo, et al. Facing COVID-19 via anti-inflammatory mechanism of action: Molecular docking and pharmacokinetic studies of six-anti-inflammatory compounds derived from Passiflora edulis, J. Compl. Altern. Med. Res 12 (2021) 35-51.

[23] A. Daina, M. Olivier, V. Zoete, SwissADME: a free web tool to evaluate pharmacokinetics, druglikeness and medicinal chemistry friendliness of small molecules. Sci. Rep. 7 (2017) 42717.

[24] D.E. Pires, T.L. Blundell, D.B. Ascher. pkCSM: Predicting small-molecule pharmacokinetic and toxicity properties using Graph- Based Signatures. J. Med. Chem. 58 (2015) 4066-4072.

[25] D. Lagorce, D. Douguet, M.A. Miteva, B.O. Villoutreix, Computational analysis of calculated physicochemical and ADMET properties of protein-protein interaction inhibitors, Sci. Rep. 7 (2017) 46277.

[26] N.M. Cerqueira, D. Gesto, E.F. Oliveira, D. Santos-Martins, N.F. Bras, S.F. Sousa, et al. Receptor-based virtual screening protocol for drug discovery, Arch. Biochem. Biophys. 582 (2015) 56-67.

[27] W.M. Pardridge, The blood-brain barrier: bottleneck in brain drug development, NeuroRx 2 (2005) 3-14.

[28] Martin YC. A bioavailability score. J. Med. Chem. 48 (2015) 3164-3170.

[29] A. Matondo, J.T. Kilembe, E.M. Ngoyi, C.N. Kabengele, G.N. Kasiama, E.M. Lengbiye, et al, Oleanolic acid, ursolic acid and apigenin from Ocimum basilicum as potential inhibitors of the SARS-CoV-2 Main protease: A molecular docking study, Int. J. Path. Altern. Res. 6 (2021) 1-16. 